\title{
A CONCENTRAÇÃO FUNDIÁRIA NO ESTADO DE MATO GROSSO: leituras a partir da análise dos Censos Agropecuários 1985- 2017
}

\section{LAND CONCENTRATION IN THE STATE OF MATO GROSSO: readings from the Analysis of the Agricultural Census 1985-2017}

\author{
Helene Lima da Costa \\ Mestranda em Geografia pela Universidade Federal de Mato Grosso, Cuiabá, MT, Brasil \\ helene-1c@hotmail.com
}

Onélia Carmem Rossetto

Pesquisadora Associada ao Programa de Pós-Graduação em Geografia, Universidade Federal de Mato Grosso, Cuiabá, MT, Brasil carmemrossetto@gmail.com

\begin{abstract}
Resumo
A realidade agrária dos países latino-americanos é marcada pela concentração de terras e pelos conflitos entre as classes sociais. Todavia, em países como o Brasil registra-se a Política Nacional de Reforma Agrária (PNRA) que visa facilitar a desconcentração fundiária, embora nem sempre obtenha resultados positivos. O principal instrumento que apresenta dados estatísticos sobre o espaço agrário nacional é o Censo Agropecuário realizado periodicamente pelo Instituto Brasileiro de Geografia e Estatística (IBGE), que deveria ser publicado de dez em dez anos. No entanto, este período nem sempre é respeitado, como correlato ao contexto agrário nacional e estadual apresentam atributos que, em determinados aspectos, não correspondem à realidade econômica e social. Tal fato pode influenciar na proposição de políticas, planos e programas de desconcentração e regularização fundiária. Com base nesse pressuposto, o presente artigo visa analisar as características da concentração fundiária no Estado de Mato Grosso, tendo como aporte metodológico a pesquisa documental por meio dos Censos Agropecuários publicados entre 1985 e 2017. Conclui-se que a estrutura fundiária concentrada se mantém em todos os momentos históricos e que a introdução das inovações técnicas na agropecuária está resultando na diminuição da oferta de trabalho e na qualidade de vida dos trabalhadores rurais.
\end{abstract}

Palavras-chave: Mato Grosso. Censo Agropecuário. Concentração Fundiária. Tecnologia.

\section{Abstract}

Land concentration and conflicts between social classes mark the agrarian reality of the Latin American countries, however, in countries such as Brazil, there is the National Policy of Agrarian Reform (PNRA), which aims to facilitate land decentralization, although not always get positive results. The main instrument that presents statistical data

CAMPO-TERRITÓRIO: revista de geografia agrária, v. 14, n. 32, p. 84-99, abr., 2019 
on the national agrarian space is the Agricultural Census, periodically conducted by the Brazilian Institute of Geography and Statistics (IBGE), which should be published every ten years, however, this period is not always respected, as a correlate to national and state agrarian context have attributes that, in certain respects, do not correspond to economic and social reality. This fact may influence the proposition of policies, plans, and programs of decentralization and land regularization. Based on this assumption, this article aims to analyze the characteristics of land concentration in the State of Mato Grosso, having as methodological support the documentary research through the Agricultural Census published between 1985 and 2017. The conclusion is that the concentrated land structure is maintained at all historical times and the introduction of technical innovations in agriculture is resulting in a decrease in labor supply and quality of life of rural workers.

Keywords: Mato Grosso. Agricultural Census. Land concentration. Technology.

\section{Introdução}

A realidade agrária dos países latino-americanos é marcada pela concentração de terras e pelos conflitos entre as classes sociais que resistem à divisão das propriedades. Todavia, em países como o Brasil registra-se a Política Nacional de Reforma Agrária (PNRA) que visa facilitar a desconcentração fundiária, embora nem sempre obtenha resultados positivos.

Girardi (2017) analisa a questão agrária brasileira e ressalta os problemas originados pelo desenvolvimento do capitalismo no campo e reitera as afirmações de Oliveira (2007), cujas assertivas estão centradas na conceituação do modo capitalista de produção como produto de um processo contraditório que não está limitado apenas à produção, mas também à circulação de mercadorias em uma lógica de acumulação de capital. Esse movimento gera a subordinação de qualquer esfera da agricultura ao mercado capitalista que mantém a alta produtividade e a concentração de terra e renda.

Tais características podem ser evidenciadas pelo principal instrumento que apresenta dados estatísticos sobre o espaço agrário nacional, o Censo Agropecuário. Realizado periodicamente pelo Instituto Brasileiro de Geografia e Estatística (IBGE), deveria ser publicado de dez em dez anos. No entanto, este período nem sempre é respeitado, como correlato ao contexto agrário nacional e estadual apresentam atributos que, em determinados aspectos, não correspondem à realidade econômica e social. Tal fato pode influenciar na proposição de políticas, planos e programas de desconcentração e regularização fundiária.

CAMPO-TERRITÓRIO: revista de geografia agrária, v. 14, n. 32, p. 84-99, abr., 2019 
Com base nesse pressuposto, o presente artigo visa analisar as características agrárias em escala estadual, especificamente no Estado de Mato Grosso que tem cerca de $60 \%$ da sua área territorial destinada à agricultura monocultora de grãos direcionados à exportação, principalmente no Norte do Estado, onde há predominância do agronegócio, evidenciando a tendência à elevada concentração da estrutura fundiária. Moreno (1999) atribui tal característica ao processo de ocupação e disputa do território mato-grossense, marcado por intenso jogo de interesses, não somente pelos proprietários de terras, mas também pelos políticos e funcionários de diversos órgãos que facilitaram a regularização de grandes áreas nas mãos de poucas pessoas.

Os aportes metodológicos estiveram centrados na pesquisa documental, por meio dos indicadores quantitativos apresentados nos Censos Agropecuários publicados entre 1985 e 2017, a saber: 1985; 1995-1996; 2006; 2017. É importante ressaltar que cada Censo analisa categorias diferentes, o que impossibilita comparações exatas entre os anos pesquisados. Contudo, a junção dos dados se constitui em importante instrumento que proporciona o desvelar da realidade agrária. Selecionou-se como categorias de análise: a) relação entre a quantidade de pessoas trabalhando no campo e o número de tratores adquiridos; b) tamanho médio dos estabelecimentos rurais (ha), segundo as classes de área (ha); c) número de propriedades rurais. Os dados foram analisados com base na pesquisa bibliográfica e demonstrados através dos textos e da linguagem gráfica.

Assim, o artigo está organizado em quatro seções além da presente introdução. $\mathrm{Na}$ primeira registra-se a pluralidade das perspectivas teóricas sobre a concentração da estrutura fundiária e os reflexos do processo de modernização da agricultura no país. Na sequência realiza-se a retomada do contexto histórico no âmbito nacional e estadual. Já a terceira seção busca desvelar as características agrárias contemporâneas no período 19852017, apresentando dados quantitativos que envolvem múltiplas escalas geográficas, fato que facilita a análise. E por último, as considerações finais ressaltam as principais ponderações a respeito da temática pesquisada. 
A concentração fundiária no estado de Mato Grosso:

Helene Lima da Costa

leituras a partir da análise dos Censos Agropecuários 1985-2017

Onélia Carmem Rossetto

Concentração da Estrutura Fundiária e Modernização da Agricultura: Perspectivas teóricas

As perspectivas teóricas sobre a concentração da estrutura fundiária e os reflexos do processo de modernização da agricultura no país são eminentemente plurais, embora as análises tenham em comum as características do modo capitalista, no qual a realidade brasileira encontra-se inserida. A concentração da terra, ou seja, a estrutura fundiária concentrada é colocada como base dos conflitos agrários e é considerada como um problema estrutural do capitalismo.

Oliveira (2007) ressalta as diferentes interpretações do processo de implantação do modo capitalista de produção de forma plena no espaço agrário, esclarecendo que se daria por duas formas: a) pela destruição do campesinato ou pequeno produtor familiar de subsistência, através das diferentes formas da sua inserção no mercado capitalista, o que provocaria uma diferenciação interna na classe camponesa, correlatamente, ter-se-ia a configuração de duas classes sociais distintas: os camponeses ricos, que seriam os pequenos capitalistas rurais; e os camponeses pobres, que se tornariam trabalhadores assalariados ou proletários. b) pelo processo de modernização do latifúndio, via introdução de tecnologia moderna, o que permitiria a transformação dos latifúndios em empresas rurais capitalistas.

Assim, os interesses dos camponeses ricos (pequenos capitalistas) e dos latifundiários (grandes capitalistas) estariam unificados e aos camponeses pobres restaria apenas a alternativa de subordinação como trabalhadores assalariados a serviço do capital. Pactuando de tais assertivas, Saquet (2006) assevera que com a expansão do Modo Capitalista de Produção ocorrem grandes transformações na agricultura familiar, integrando-se e sendo integrada cada vez mais ao processo geral de reprodução ampliada do capital, através da circulação simples de mercadorias.

Com a modernização da agricultura, Saquet (2006) ressalta que os agentes do capital envolvem e subordinam agricultores familiares. Para o autor, antes da chamada modernização agrícola, o processo de sujeição e exploração ocorria mediado pelos comerciantes/negociantes. A partir de 1960 e principalmente de 1970, passou a ser mediado por cooperativas empresarialmente desenvolvidas e por grandes empresas integradoras em que há uma vinculação contratual de compra e venda.

CAMPO-TERRITÓRIO: revista de geografia agrária, v. 14, n. 32, p. 84-99, abr., 2019 
Silva (1993) ressalta que o processo de modernização da agricultura teve como consequência um modelo econômico que alterou o denominado modelo de substituição de importações, devido à industrialização nacional e à consequente modernização do sistema agrário e a formação dos Complexos Agroindustriais (CAIs). O referido processo ocorreu sob os auspícios do Estado e se deu a partir da integração intersetorial entre três elementos: as indústrias que produzem para a agricultura, a agricultura (moderna) propriamente dita e as agroindústrias processadoras.

Dessa forma, a modernização da agricultura influenciou as desigualdades socioeconômicas, ampliou a concentração de terras e favoreceu o agronegócio em detrimento da agricultura familiar, inserindo-a no processo de perda de autonomia e consequente proletarização. Garcia e Palmeira (2001) registram que passa a ocorrer sua pauperização, pois, deixam de ser proprietários dos meios de produção para se submeterem ao trabalho assalariado.

Ianni (2004, p. 120), ao discutir a gênese do proletariado rural, afirma que o processo começa com a transformação do agricultor de trabalhador livre para trabalhador assalariado, isto é, em vendedor de força de trabalho. Por outro lado, os movimentos sociais contra-hegemônicos lutam pela desconcentração da terra e da renda, exigindo a reforma agrária e melhor qualidade de vida para os trabalhadores do campo.

O processo de proletarização do trabalhador rural contribui também para sua vulnerabilidade social, a escravidão contemporânea, denominada de trabalho análogo ao de escravo, trabalho forçado por dívida, degradante, obrigatório, uma prática ilegal, reconfigurada pelo capital para garantir a maior exploração da classe trabalhadora.

O trabalho escravo contemporâneo resulta do movimento concentrador, excludente e violento da (re)produção capitalista que segundo Santana (2018, p. 2):

[...] cria e recria as condições necessárias para a sua utilização mesmo quando seu fulcro central é o trabalho livre assalariado. (...) O capital trouxe junto às benesses da ciência, a intensificação dessas relações anacrônicas de trabalho, (...) por estarem diretamente relacionadas ao desemprego estrutural.

A substituição da mão de obra humana pela moderna tecnologia resulta em grande massa de desempregados rurais disponíveis para serem explorados pelo capital, tanto nas áreas rurais como nas áreas urbanas devido ao processo de migração. Nas

CAMPO-TERRITÓRIO: revista de geografia agrária, v. 14, n. 32, p. 84-99, abr., 2019 
A concentração fundiária no estado de Mato Grosso:

Helene Lima da Costa

leituras a partir da análise dos Censos Agropecuários 1985-2017 Onélia Carmem Rossetto

cidades, os trabalhadores rurais são facilmente aliciados pelo capital, permanecendo no ciclo vicioso de exploração e vulnerabilidade social e econômica.

\section{A questão agrária nos contextos nacional e estadual}

A questão agrária na América Latina se configura com a dependência agrícola que os países têm em sua economia. Em muitos deles essa atividade econômica ainda é feita como no período colonial, ou seja, propriedades muito grandes que pertencem a poucas famílias e quase toda produção é destinada à exportação. Como correlato, a falta de terras para que todos possam cultivar faz com que surjam áreas de conflitos.

Essa relação fundiária conturbada fez com que em vários países fossem criados projetos de reforma agrária, com o objetivo de melhorar a distribuição de algo tão importante, que poderia amenizar os problemas relacionados à desigualdade social no Brasil.

O modelo de estrutura agrária - ou seja, a forma como a terra está distribuída - é caracterizada no Brasil pela intensa concentração fundiária. Na década de 1980, alguns estudiosos definiam a questão agrária no Brasil como na Europa no período do feudalismo, ou seja, ainda seria um reduto de relações feudais. Porém, de acordo com Prado Jr. (1981), no Brasil o processo ocorreu de forma diferente, pois na base e origem de nossa estrutura e organização agrária encontramos a grande exploração rural, que se manteve até os dias atuais, quando se adaptou ao sistema capitalista de produção através de um processo ainda em pleno desenvolvimento e não inteiramente completado de substituição do trabalho escravo pelo trabalho juridicamente livre.

As terras no Brasil eram originalmente públicas, visto que sob o domínio dos povos indígenas não possuíam proprietários privados. Porém, depois da chegada dos portugueses em 1500 a situação foi alterada, pois, eles a tornaram como bem do estado. Segundo Jahnel (1987), não existia a posse legal sobre a terra, mas concessões reais do governo português, o qual poderia tomar suas terras quando desejasse, as capitanias hereditárias eram de sua propriedade.

A partir dos anos 1550, os portugueses dividiram o território do Brasil em doze capitanias hereditárias para facilitar a administração das terras (MORENO, 1999). Quem ficou responsável por elas eram pessoas próximas ao rei ou membros da nobreza

CAMPO-TERRITÓRIO: revista de geografia agrária, v. 14, n. 32, p. 84-99, abr., 2019 
portuguesa, chamados de donatários que possuíam o direito de nomear autoridades jurídicas ou administrativas e de instituir um sistema tributário em sua capitania.

Porém, o início da colonização do território brasileiro ocorreu mais significativamente através das Sesmarias (1822) - que nada mais era que a doação de grandes extensões de terras particulares. Jahnel (1987) ressalta que as sesmarias foram utilizadas principalmente para o plantation da cana-de-açúcar, sobretudo no litoral nordestino.

Posteriormente, com a criação da Lei de Terras em 1850, que tinha como intenção implícita evitar que o imigrante e o negro liberto tivessem acesso à terra, almejando perpetuar a desigualdade social e fundiária no Brasil, houve a consolidação da terra como mercadoria, pois somente quem tivesse dinheiro para comprar é que teria acesso a ela. Portanto, a estrutura agrária continuou concentrada (OLIVEIRA, 2007).

Na década de 1930, de acordo com Moreno (1999), ocorreu o incentivo do governo em povoar áreas afastadas como parte da região Centro-Oeste e Norte do Brasil, através da "Marcha para o Oeste" - auge da multiplicação das pequenas propriedades. A alta concentração de terras continuou aumentando, principalmente as ligadas às empresas multinacionais. Segundo Oliveira (2007), além de povoar os lugares mais distantes, o objetivo do governo era proteger contra os exércitos inimigos. Nessa perspectiva, a grande propriedade no Brasil vem crescendo sempre a taxas superiores às das pequenas, acompanhada de uma rápida expansão das fronteiras agrícolas, que só favorece essa concentração em vez de uma melhor distribuição de terras.

Pesquisa realizada pela parceria Núcleo de Estudos Agrários e Desenvolvimento Rural (NEAD), Ministério do Desenvolvimento Agrário e Fundação Instituto de Pesquisas Econômicas (FIPE), intitulada: "A importância do agronegócio familiar no Brasil", mostra que na região Centro-Oeste a característica central do agronegócio é o seu caráter patronal, baseado na grande propriedade e na plantation voltada para a exportação. Os estados utilizam insumos de ponta e tecnologia de última geração. A maior parte do PIB do setor concentra-se na produção de grãos, que é responsável por mais de 50\% do PIB do Mato Grosso e de Goiás (GUILHOTO, 2007).

Em se tratando especificamente do Estado de Mato Grosso, apesar de já existir diversos povos indígenas como os Bororos e os Parecis, o estado foi povoado no começo do século XVIII quando o ouro foi descoberto pelos bandeirantes. Assim, as terras foram

CAMPO-TERRITÓRIO: revista de geografia agrária, v. 14, n. 32, p. 84-99, abr., 2019 
intensamente ocupadas com o mesmo processo que o Brasil: Sesmarias, Lei de Terras, Marcha para o Oeste, e de forma mais concentrada (a partir de meados do século XX), através das colonizadoras, principalmente se tratando da região Norte do estado.

Rossetto $(2011 ; 2015)$ ressalta que os dois principais fatores que contribuíram com o povoamento de forma mais intensa em direção à região Norte do estado de Mato Grosso foram a construção das rodovias federais e as ações das colonizadoras oficiais e particulares. Entre 1970 e 1990, o INCRA titulou definitivamente mais de 3.600 milhões de ha às margens das rodovias federais e 3.400 milhões foram titulados provisoriamente para as empresas de colonização (MORENO, 1999).

As empresas tiveram um papel de suma importância, pois, traziam camponeses já com experiência em atividades agrícolas no Paraná para desbravar territórios em Mato Grosso. Segundo Rossetto (2011), devido às condições do solo e clima do Norte do estado, à baixa capitalização e à precária assistência técnica, parte dos camponeses com pouco poder aquisitivo perderam tudo que investiram e venderam suas propriedades aos grandes latifundiários.

Outra consequência da ação dessas colonizadoras, principalmente após os anos 80, foi o aumento dos conflitos por terra por parte dos indígenas, posseiros, colonos e grileiros. Assim surgiu a Comissão da Pastoral da Terra (CPT) que incentivou o aumento da pressão social feita pelos camponeses em sua luta pela terra. Em contrapartida a essas categorias, nascia a União Democrática Ruralista (UDR) que defendia os latifundiários para a formação da bancada ruralista no congresso, presente até os dias atuais na defesa de seus próprios interesses (OLIVEIRA, 2016).

Portanto, é possível observar que o processo de formação da estrutura agrária brasileira e mato-grossense priorizou a grande lavoura, reservando ao campesinato uma posição subordinada e periférica.

No último relatório de Desenvolvimento (PNUD) divulgado em 2017, o país ocupou o $79^{\circ}$ lugar entre 188 nações no ranking de IDH, que leva em conta indicadores de educação, renda e saúde. Essa desigualdade também é apresentada no relatório da Pesquisa Nacional por Amostra de Domicílios Contínua (PNAD Contínua) que revela que 889 mil pessoas integram o grupo de $1 \%$ mais rico, com rendimento médio de 27 mil reais mensais; e 44,4 milhões é o número de pessoas que integram o grupo de $50 \%$ com renda mensal de 747 reais.

CAMPO-TERRITÓRIO: revista de geografia agrária, v. 14, n. 32, p. 84-99, abr., 2019 
De acordo com Oliveira (2007), no Norte mato-grossense os grileiros utilizavam procurações falsas para se apropriarem de outras terras, fato que o autor denomina como grilagem legalizada. Moreno (1999) conclui que sempre houve um favorecimento por parte do estado de Mato Grosso e dos funcionários dos órgãos competentes para que fossem regularizadas terras através de mecanismos de burla, tal processo perdura até os dias atuais.

Entretanto, é importante ressaltar que a luta pela terra através dos movimentos socioterritoriais provoca relativa desconcentração fundiária. De acordo com dados do Relatório do Banco de Dados da Luta pela Terra (Dataluta/Mato Grosso) (GECA, 2016), o Estado possui 578 assentamentos rurais resultantes do processo de reforma agrária. Conforme Oliveira (2007), a primeira característica do "novo campo" brasileiro, no que diz respeito às relações de produção sob os moldes do capitalismo, é que o processo produtivo não é mais controlado pelo agricultor e sim pela indústria. Outra característica é a força de trabalho familiar que tem um papel importantíssimo e tem aumentado numericamente de modo expressivo.

Essas características configuram as transformações que o campo vem sofrendo ao longo dos anos. Devido ser uma atividade que consiste no uso do solo para o cultivo de elementos para assegurar a subsistência alimentar da população, a agricultura é a mais importante atividade econômica da sociedade. A agricultura mundial é muito diversificada, não somente na diversidade dos produtos, mas nas relações de produção. Essa atividade econômica obteve uma nova caracterização tendo o capitalismo como o principal requisito para essa mudança.

\section{O desvelar das características agrárias contemporâneas: Censos Agropecuários 1985-2017}

A análise dos dados preliminares do Censo Agropecuário 2017 (BRASIL, 2018) permite constatar que a área ocupada por estabelecimentos agropecuários no Brasil cresceu quase 16,5 milhões de hectares (alta de 5\% nos últimos 10-11 anos) e houve a redução de $2 \%$ no número das propriedades, ou seja, a área aumentou. Mas o número de proprietários continua relativamente igual, revelando a manutenção da concentração fundiária. Os dados mostram que Mato Grosso e Pará são os estados que mais tiveram 
altas: 6.142.108 e 6.752.341 hectares, respectivamente, em Mato Grosso cresceu a quantidade de lavouras e no Pará, as pastagens.

A análise dos dados referentes à quantidade de pessoas trabalhando no campo e vivendo totalmente dessa atividade em comparação com o número de tratores no período entre 1985 e 2017 é demonstrada no Gráfico 1.

Gráfico 1: Brasil - Relação entre a quantidade de pessoas trabalhando no campo e o número de tratores adquiridos $(1985,1995-1996,2006,2017)$

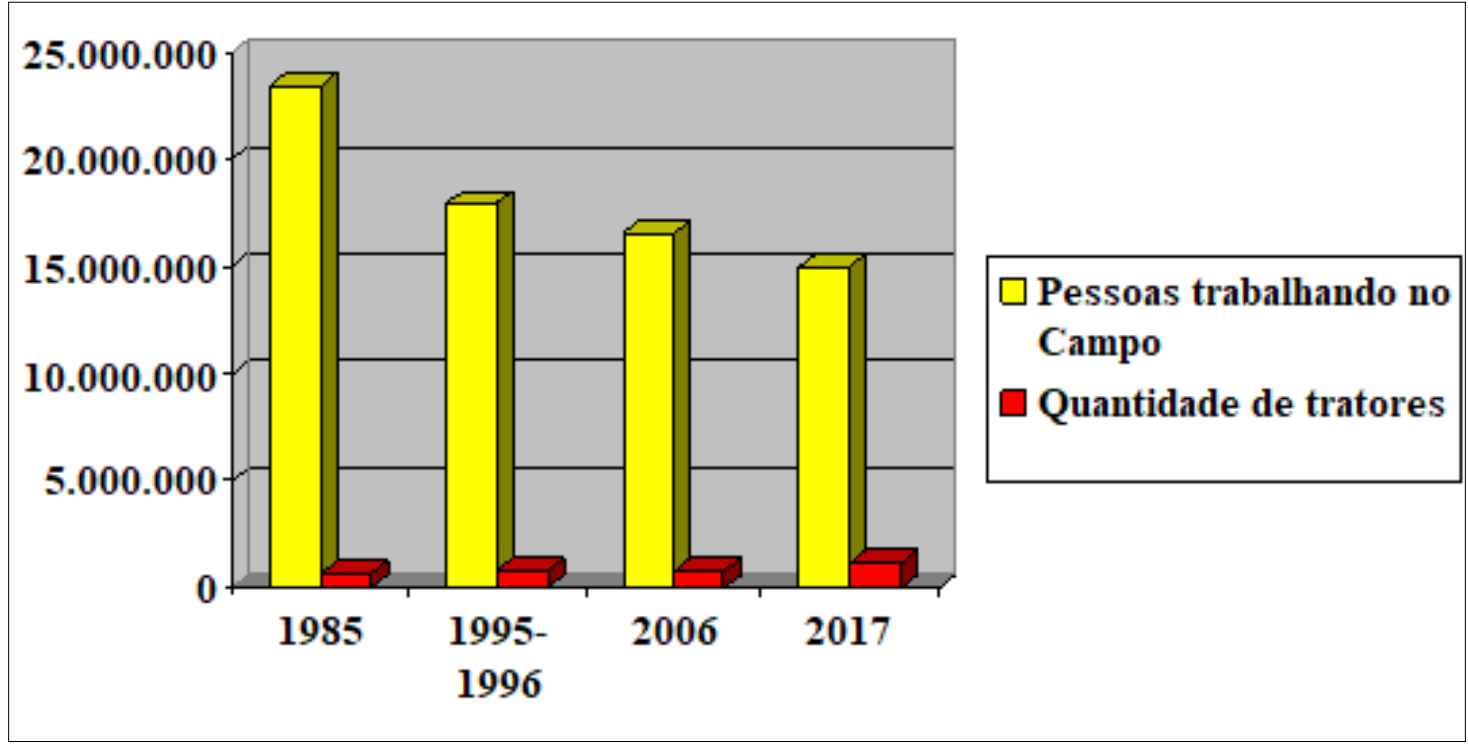

Fonte: BRASIL, 1985; 1995; 2009; 2018.

Org.: Helene Lima Costa, 2018.

O contexto apresentado no Gráfico 1 nos permite analisar que, no Brasil, a introdução das modernas técnicas de manejo através de um veículo simples, o número de tratores. Observa-se que desde 1985 está ocorrendo a diminuição da ocupação das pessoas com as atividades agrícolas que no referido ano eram 23.394.919 pessoas, em 1995-1996 eram 17.930.890, em 2006 eram 16.568.205 e em 2017 totalizaram 15.036.978 pessoas demonstrando a substituição da mão de obra por tecnologia e consequentemente a diminuição da oferta de empregos em áreas rurais.

Estudos realizados por Paulino (2015) mostram que quanto menores os estabelecimentos, maior a capacidade de geração de empregos e renda. Portanto, é óbvia a diminuição de pessoas trabalhando no campo devido à alta concentração de terras no estado. É interessante destacar que quando analisamos os dados referentes ao uso de tratores, os números nos mostram um dos motivos pelos quais essa diminuição ocorre: a

CAMPO-TERRITÓRIO: revista de geografia agrária, v. 14, n. 32, p. 84-99, abr., 2019 
quantidade de máquinas dobrou no mesmo período citado. Assim, em 1985 eram 665.280 tratores, 1995-1996, eram 803.742, em 2006, 820.718 e em 2017, 1.228.634 máquinas.

No Estado de Mato Grosso, um exemplo interessante do intensivo uso de tecnologia no campo é a irrigação, pois, o número de estabelecimentos agropecuários que passaram a utilizar esse método cresceu 52,3\% no período entre 2006 e 2017. Ademais, a agricultura de precisão é utilizada em larga escala nas grandes propriedades monocultoras. Entretanto, os censos em análise registram principalmente o número de tratores que em 1985 eram 19.534 unidades, em 1995-1996 eram 32.752, em 2006 eram 42.330 e em 2017 totalizaram 71.042, evidenciando a rápida substituição da mão de obra humana pela tecnologia.

Sobre o assunto, Gerardi (1980) afirma que o conceito de modernização é relativo e apresenta expressão espacial porque distingue agricultores em graus variados de modernização, e expressão temporal porque a agricultura evolui através das transformações das técnicas, passando de tradicional à moderna no decorrer do tempo. Na perspectiva da autora, a introdução gradativa da tecnologia resulta na exclusão do trabalhador do campo, diminuição de emprego e renda e da qualidade de vida da população.

Na perspectiva de Andrioli (2016), além do desemprego rural, a tecnologia resulta em um meio de controle social, pois, pode ocupar a força de trabalho de forma contínua e intensa, de modo que os trabalhadores não tenham controle sobre o ritmo, a quantidade e a qualidade do seu trabalho. Dessa forma, o processo produtivo dos agricultores é gradualmente condicionado pela lógica do avanço técnico, orientado aos interesses capitalistas de transformação, dominado e controlado por corporações agrícolas.

Saquet (2006) esclarece que a territorialização do capital no espaço agrário brasileiro, articulado ao Estado, ocorre através de atividades tipicamente capitalistas, com trabalho assalariado e em grandes e médias propriedades. Considera ainda que, a mecanização da agricultura ocorre de forma desigual entre as diferentes localidades do país, diminuindo a oferta de empregos; e gera a proletarização de filhos de agricultores familiares, o que impossibilita a reprodução de jovens no espaço agrário através da migração destes para cidades.

CAMPO-TERRITÓRIO: revista de geografia agrária, v. 14, n. 32, p. 84-99, abr., 2019 
As alterações na forma de organizar a produção agrícola estão atreladas aos interesses do Estado e dos grupos econômicos capitalistas. Segundo o Censo Agropecuário 2006 (BRASIL, 2009), Mato Grosso era ocupado por 86.167 estabelecimentos de agricultura familiar camponesa, em 4.884.212 ha, e por 26.811 estabelecimentos não familiares, distribuídos em um espaço de 42.921 .302 ha. Rossetto (2011) ressalta que a maior parte do território mato-grossense era ocupada por propriedades com área acima de 4 módulos fiscais, considerados não familiares, utilizados principalmente para o cultivo da soja e do algodão em grandes áreas monocultoras integradas à agropecuária moderna.

O Relatório de Dados Preliminares do Censo Agropecuário 2017 (BRASIL, 2018) não possibilita uma informação comparativa, uma vez que não apresenta dados específicos para agricultura familiar e não familiar. Mas revela que o número total de propriedades rurais aumentou de 112.978 em 2006 para 118.676 em 2017.

Analisando o tamanho médio das propriedades rurais da região Centro-Oeste em 2017 (Gráfico 2), é notória a concentração de terras existentes em Mato Grosso que possui 118.676 estabelecimentos rurais, distribuídos em 54.830.819 ha; Mato Grosso do Sul possui uma área total de 29.159.983 ha com 70.710 estabelecimentos rurais; Goiás uma área de 26.362.901 ha com 152.089 estabelecimentos; e o Distrito Federal uma área de 257.047 ha e 5.246 estabelecimentos rurais.

Gráfico 2: Centro-Oeste: Tamanho Médio dos Estabelecimentos Rurais (2017)

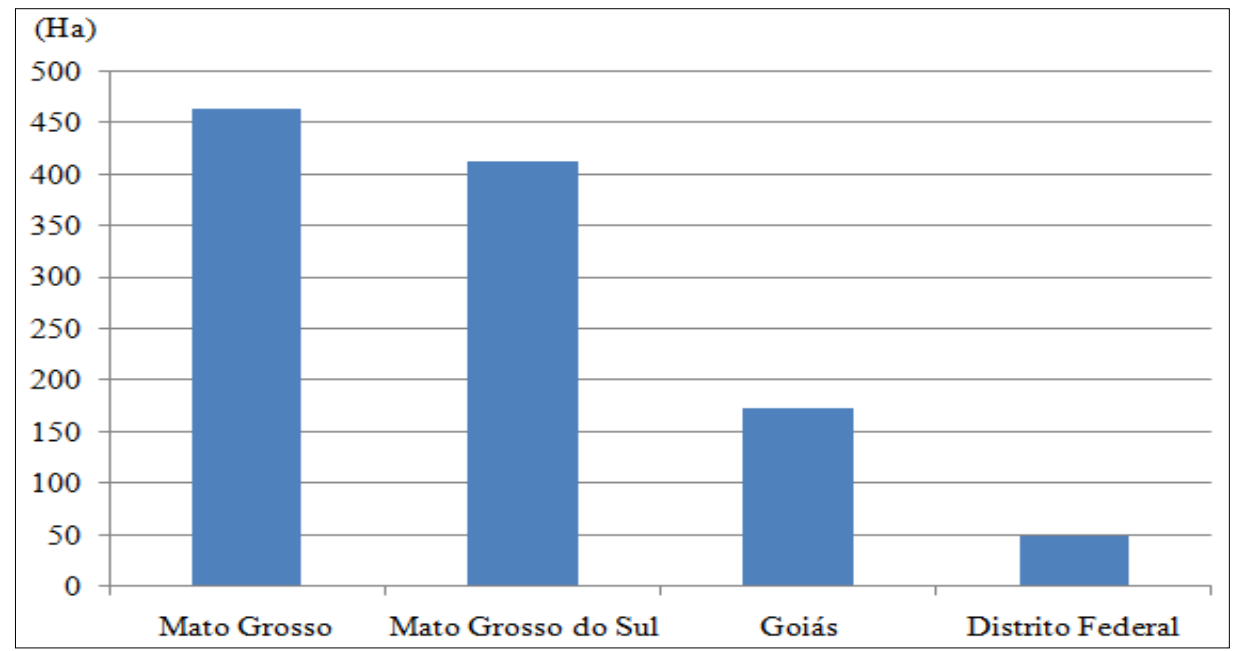

Fonte: Brasil, 2018.

Org.: Helene Lima Costa e Clayton Ferreira Dal Pozzo. 
Essa alta concentração é mais evidente na mesorregião Norte do estado, notadamente no eixo da BR-163, cujos municípios surgiram no processo de expansão da fronteira agrícola e atualmente constituem o território do agronegócio. De acordo com Rossetto (2011), no eixo da BR-163 o número de assentamentos da reforma agrária é 231,56\% menor que no Pantanal Mato-grossense, demonstrando que a desconcentração fundiária onde predomina a monocultura destinada à exportação é um processo mais difícil que em áreas onde predomina a pecuária semiextensiva em fase de modernização

A estrutura fundiária concentrada é evidenciada pelo tamanho médio dos estabelecimentos (Ha) segundo as classes de áreas (Tabela 1).

Tabela 1: Mato Grosso: Tamanho médio dos estabelecimentos (ha), segundo as classes de área (ha) (2017)

\begin{tabular}{lcl}
\hline Classes de Área (Ha) & $\begin{array}{c}\text { Número de } \\
\text { Estabelecimentos rurais }\end{array}$ & Área $(\mathrm{Ha})$ \\
\hline Menos que 1 ha & 2627 & 879 \\
De 1 a 10 ha & 15268 & 66638 \\
De 10 a menos de 50 ha & 39721 & 1088522 \\
De 50 a menos de 100 ha & 23883 & 1595327 \\
De 100 a menos de 500 ha & 22394 & 4634585 \\
De 500 a menos de 10000 ha & 13609 & 27838532 \\
De 10000 e mais ha & 868 & 19606336 \\
\hline
\end{tabular}

Fonte: Brasil, 2018.

Org.: Helene Lima Costa, 2018.

Com base na leitura da tabela conclui-se que de acordo com a elevação das classes de área, diminuem o número de estabelecimentos rurais, demonstrando a estrutura fundiária concentrada, onde apenas 868 estabelecimentos rurais possuem uma área de 19.606.336 hectares.

Por outro lado, ao comparar-se os dados de 2017 com os dados de 2006, registrase o aumento de 3.728 estabelecimentos na classe de área de 1 a 10 hectares e 800 estabelecimentos na classe de área de 10 a menos de 100 hectares. Ademais, ocorreu um aumento da área ocupada de 9.025 e 101.592 hectares, respectivamente. Tais dados possibilitam concluir que, embora ainda incipiente, está ocorrendo paulatinamente um processo de desconcentração fundiária no Estado de Mato Grosso, evidenciado pelo aumento do número de assentamentos rurais que resultam da constante luta dos movimentos sociais, mas o referido fato ainda não influencia nos indicadores de concentração fundiária. 
Em síntese, a análise da Questão Agrária em Mato Grosso possibilita constatar que o mesmo é um estado cuja distribuição de terras é altamente concentrada, o que caracteriza altos níveis de desigualdade social. Tal processo resulta dos diferentes períodos históricos de conquista e formação do território, principalmente da política da Marcha para o Oeste, das ações das colonizadoras e da partilha das terras de forma desigual, priorizando a grande propriedade rural.

\section{Considerações Finais}

Em Mato Grosso, as técnicas usadas pelo agronegócio primam pela agricultura de precisão atrelada principalmente ao mercado internacional, que se caracteriza pela pouca empregabilidade da mão de obra rural, principalmente, dos trabalhadores que possuem baixa qualificação tecnológica e baixo nível instrucional adquirido através da educação formal.

A consequência para essa parcela de trabalhadores reside no êxodo rural, na exclusão social e na ausência ou fragilidade dos direitos civis e sociais, principalmente porque a política de inserção tecnológica atua em descompasso com as políticas de acesso à educação e formação tecnológica, formando um conjunto de trabalhadores vulneráveis que se sujeitam a quaisquer condições de trabalho para conseguirem assegurar sua sobrevivência. Portanto, disponíveis para serem explorados pelos detentores do capital e dos meios de produção.

A forma como os Censos Agropecuários apresentam as informações dificultam estudos comparativos e exigem grande esforço por parte dos pesquisadores. Entretanto, possibilitam revelar o panorama da concentração fundiária e a intencionalidade das fontes oficiais. A análise aqui apresentada revela, nesse sentido, que ocorre a manutenção das características em todos os censos e prevalecem grandes desafios na luta pela divisão mais equitativa da terra e da renda.

\section{Referências}

ANDRIOLI, Antônio Inácio. Soja orgânica versus soja transgênica: um estudo sobre tecnologia e agricultura familiar no Noroeste do Estado do Rio Grande do Sul. Chapecó: UFFS, 2016.

CAMPO-TERRITÓRIO: revista de geografia agrária, v. 14, n. 32, p. 84-99, abr., 2019 
BRASIL. Censo Agropecuário: 1985. Rio de Janeiro: IBGE, 1985.

Censo Agropecuário: 1995/96. Rio de Janeiro: IBGE, 1995.

Censo Agropecuário 2006. Agricultura Familiar. Primeiros Resultados. Brasil, Grandes Regiões e Unidades da Federação. Rio de Janeiro: IBGE, 2009.

2018

Censo Agropecuário 2017. Resultados Preliminares. Rio de Janeiro: IBGE,

Relatório Anual Brasil 2017. Brasília: Programa das Nações Unidas para o

Desenvolvimento, 2018. Disponível em: $<$ http://www.br.undp.org/content/brazil/pt/home/library/relatoriosanuais/relatorio-anualpnud-brasil---2017.html>. Acesso em: 10 mai. 2018.

GARCIA, Afrânio; PALMEIRA, Moacir. Transformação Agrária. In: SACHS, Ignacy; WILHEM, Jorge; PINHEIRO, Paulo Sergio (Orgs.). Brasil: um século de transformações. São Paulo: Companhia das Letras, 2001.

GECA. Relatório Dataluta Mato Grosso. Disponível em: <http://www.ippri.unesp.br/ Home/posgraduacao/desenvolvimentoterritorialnaamericalatinaecaribe/relatorio_datalut a_mt_2013.pdf>. Acesso em: 30 set. 2018.

GERARDI, Lucia Helena de O. Algumas reflexões sobre modernização da agricultura. Geografia, Rio Claro, v. 5, n. 9/10, p. 19-34, 1980.

GIRARDI, Eduardo Paulon. Atlas da Questão Agrária Brasileira. Presidente Prudente: UNESP/NERA, 2017. Disponível em: <www.atlasbrasilagrario.com.br〉. Acesso em: 05 jul. 2018.

GUILHOTO, Joaquim José Martins et al. A Importância da Agricultura Familiar no Brasil e em seus Estados. 35 ${ }^{\circ}$ Encontro Nacional de Economia da ANPEC, Recife, 2007. Trabalhos selecionados... $\quad$ Recife, 2007. Disponível em: $<$ http://www.anpec.org.br/encontro2007/artigos/A07A089.pdf>. Acesso em: 12 jul. 2018.

IANNI, Octávio. Origens Agrárias do Estado Brasileiro. São Paulo: Brasiliense, 2004.

JAHNEL, Tereza. As Leis de Terra no Brasil. Boletim Paulista de Geografia, São Paulo, n. 65, p. 105-116, 1987.

MORENO, Gislaene. O processo histórico de acesso à terra em Mato Grosso. Geosul, Florianópolis, v. 14, p. 67-90, jan/jun. 1999.

OLIVEIRA, Ariovaldo Umbelino. Modo de Produção Capitalista, Agricultura e Reforma Agrária. São Paulo: FFLCH, 2007.

CAMPO-TERRITÓRIO: revista de geografia agrária, v. 14, n. 32, p. 84-99, abr., 2019 
A Fronteira Amazônica Mato-Grossense: Grilagem, Corrupção e Violência. São Paulo: Iandé Editorial, 2016.

PAULINO, Eliane Tomiasi. O Descumprimento da Função Social da Terra e a Invisibilização do Latifúndio como Estratégia de Classe: o Caso de Mato Grosso. In: ALMEIDA, Rosemeire Aparecida de; SILVA, Tânia Paula da (Org.). Repercussões territoriais do desenvolvimento desigual-combinado contraditório em Mato Grosso. Campo Grande: Editora da UFMS, 2015, v. 01, p. 63-81.

PRADO JUNIOR, Caio. A questão agrária no Brasil. São Paulo: Brasiliense, 1981.

ROSSETTO, Onélia Carmem. Dinâmica Agrária e Resiliência Camponesa: Estudo Comparativo entre o Lócus do Agronegócio e o Pantanal Mato-grossense. Revista do Instituto Histórico e Geográfico de Mato Grosso, Cuiabá, n. 68 e 69, p. 47-64, jul/2011. Disponível em: <>http://www.ingmt.org.br/revistas/REVISTA\%2068-69.pdf. Acesso em: 18 ago. 2018.

Faces da Agricultura Familiar Camponesa nas Microrregiões do Alto Pantanal e Tangará da Serra - Mato Grosso; Brasil. In: ALMEIDA, Rosemeire Aparecida de; SILVA, Tânia Paula da (Org.). Repercussões territoriais do desenvolvimento desigualcombinado contraditório em Mato Grosso. Campo Grande: Editora da UFMS, 2015, v. 01, p. 41-62.

Produção do Espaço Agrário no Estado de Mato Grosso e o Processo de Concentração de Terras no Pantanal Norte Mato-grossense. In: ROSSETTO, O. C.; TOCANTINS, N (Orgs.). Ambiente Agrário do Pantanal Brasileiro: Socioeconomia e Conservação da Biodiversidade. Porto Alegre: Compasso-Lugar, Cultura, 2015. Disponível em: 〈http://issuu.com/imprensa.livre/docs/pantanal_parte_1〉. Acesso em: 1 set. 2018 .

SANTANA, Aurelane Alves. Escravidão Rural E Agronegócio Na Bahia No Século XXI (Rural Slavery And Agribusiness In Bahia In The 21st Century). Revista GeoNordeste, n. 1, p. 110-124, 2018.

SAQUET, Marco Aurélio. CAMPO-TERRITÓRIO: Considerações teóricometodológicas. CAMPO-TERRITÓRIO: Revista de Geografia Agrária, Uberlândia, v. 1, n. 1, p. 60-81, fev. 2006.

SILVA, José Graziano da. A industrialização e a Urbanização da Agricultura Brasileira. São Paulo: Perspectiva, 1993.

Recebido em 26/10/2018.

Aceito para publicação em 08/04/2019. 